TITLE:

\title{
Angular dependence of current transport characteristics in a mixed state of $\mathrm{Bi}-2223 / \mathrm{Ag}$ multifilamentary tape
}

\section{$\operatorname{AUTHOR}(\mathrm{S})$ :}

Nakamura, T; Yamamoto, T; Tsuchiya, S; Hoshino, T; Muta, I

\section{CITATION:}

Nakamura, T ...[et al]. Angular dependence of current transport characteristics in a mixed state of Bi-2223/Ag multifilamentary tape. IEEE TRANSACTIONS ON APPLIED SUPERCONDUCTIVITY 2000, 10(1): 1166-1169

\section{ISSUE DATE:}

2000-03

URL:

http://hdl.handle.net/2433/39938

\section{RIGHT:}

(c)2000 IEEE. Personal use of this material is permitted. However, permission to reprint/republish this material for advertising or promotional purposes or for creating new collective works for resale or redistribution to servers or lists, or to reuse any copyrighted component of this work in other works must be obtained from the IEEE. 


\title{
Angular Dependence of Current Transport Characteristics
}

\section{in a Mixed State of $\mathrm{Bi}-2223 / \mathrm{Ag}$ Multifilamentary Tape}

\author{
Taketsune Nakamura, Takaliro Yamamoto, Shingo Tsuchiya, Tsutormu Hoshino, \\ and Itsuya Muta, Member, MELE
}

\begin{abstract}
Wo havo invostigated current transport characteristics in a mixed state of Bi-2223/ $\Lambda_{\mathrm{g}}$ multifilamentary tape by varying the angle between the external magnotic flold and the tape surface. It was shown that the so-called glass-liquid transition magnetic fleld, which is an important parameter for applications of peraistent current mode, as well as tho critlcal curronts, was dominated by tho c-axis component (porpondicular to the tape surface) of the oxternal magnetic flold in a wide range of the field direction.
\end{abstract}

Keyunrds--Bi-2223/Ag multifilamentary tape, Curront transport charactoristics, Anisotropy, Glass-liquid transition fleld.

\section{INTRODUCTION}

Silver sheathed $\mathrm{Bi}_{2} \mathrm{Sr}_{2} \mathrm{Ca}_{2} \mathrm{Cu}_{3} \mathrm{O}_{10+\delta}$ (hereafter, stated as $\mathrm{Bi}-2223 / \mathrm{Ag}$ ) tape is a promising matcrial for such power application systems as superconducting magnots, power cables, etc, because of its long tape with high quality. Cryocooled 7 Tesla magnets using Bi-2223/Ag coils have been confirmed to be stable for operation [1]. In Detroit, experimontal tests of $120 \mathrm{~m}$ long power cables hawe boon planned. Furthermore, 500kVA-class superconducting power transformer has boen doveloped and tested successfully [2].

It's crucial to cstimate the material parameters such as critical current density for the design of the superconducting power systems. However, it's well known that the current transport property in high- $T_{\mathrm{c}}$ superconductor has a strong anisotropy with respect to the applied mannetic field direction. Therefore, it's important to take into account this magnetic anisotropy for the accurate design of the high$T_{c}$ power systems. In this study, we heve investigated the anisotropy of the critical currents and current transport characteristics in a 13i-2223/Ag multifilamontary tape. One of the salient features of curront tramsport characteristics in high- $T_{c}$ superconductors is thoir scaling characteristics with the aid of so-called glass-liquid transition mugnetic ficld $[3],[4]$. For the design of the powor systems, the importance of glass-liquid transition fickl will be discussed in due course. And arigular dependences of the critical currents and this paramotor are also to be presented.

\section{EXPERIMENTAI.}

The Bi-2223/Ag multifilamentary tapos were produced by a powder-in-tube mothod at Korea Elentrotechnology Restarch Institute (KERI). The paraneters of the sample aro show in TABLE 1 . The tape was cut carefully at $30 \mathrm{~mm}$

'E'. Nakamura, T Yammolo, S. Tsuchiya, T. Iloshino and I, Muta are with the Gralualo school of Engineering, Kyoto Univorsity, Kyoto 606-850 !, Japdr. E-mail: tk_nakeókuee.kyoto-u.ac.jp
TABIA' I

'IlHE PARAMTTERS OF ThH SAMPLE

\begin{tabular}{cc}
\hline sample & $\mathrm{Bi}-2223 / \mathrm{Ag}$ tape \\
process & PIT method \\
cross sectional area & $4.0 \mathrm{~mm}^{4} \times 0.23 \mathrm{~mm}^{4}$ \\
number of filaments & 19 \\
$\mathrm{Ag} / \mathrm{Sc}$ & 2.2 \\
critical temperature & $103.5 \mathrm{~K}$ \\
critical current density & $1.06 \times 10^{4} \mathrm{~A} / \mathrm{cm}^{2}$ \\
& $(77.3 \mathrm{~K}, 0 \mathrm{~T})$ \\
$n$-value & $34.0 \mathrm{~K}, 0 \mathrm{~T})$ \\
\hline
\end{tabular}

length for tho moasiurements. The distanco botween potential taps was $2.0 \mathrm{~mm}$. Current transport characteristics were measured with standard four-probe techniquo. In order to avoid the thermal fluctuation, the rectangular waves with the repctition frequency of $0.5 \mathrm{H}$ \% wero used as transport curronts. All measurcments wore carried out immorsed in the liquid ritrogen $(77.3 \mathrm{~K})$.

Fig.1 shows the schematics of the sample holder, which has a rotatable stage. The sample stago was conficetod to the vernier gauge set on top of the holder with a $0.2 \mathrm{~mm}$ stainless wire (not shown in Fig.1), and the angle of the stage was set by rotating the vernier gauge with the ratio at 2:1. The angilar accuracy was botter than $0,4^{\circ}$. The angle between applied magnetic field and the tape surtace was defined as $0^{\circ}$ and $90^{\circ}$ for the fiold perpondicular and parallol to the tape surfaco, respectively.

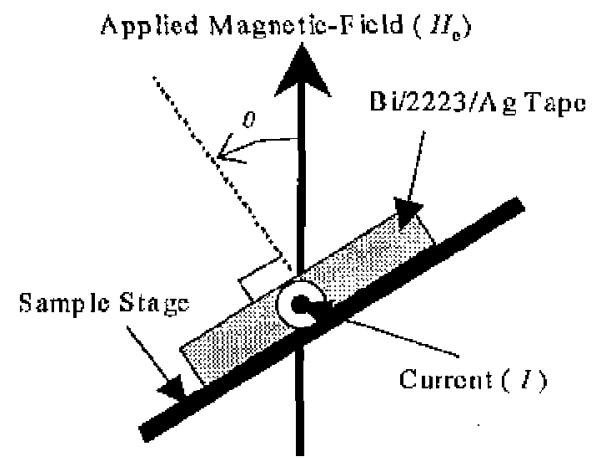

Fig. 1. Schomatics of the sample holder. Wxternal magnetic field $\left(H_{\mathrm{e}}\right)$ is always perpondicular to the currontis (I) 


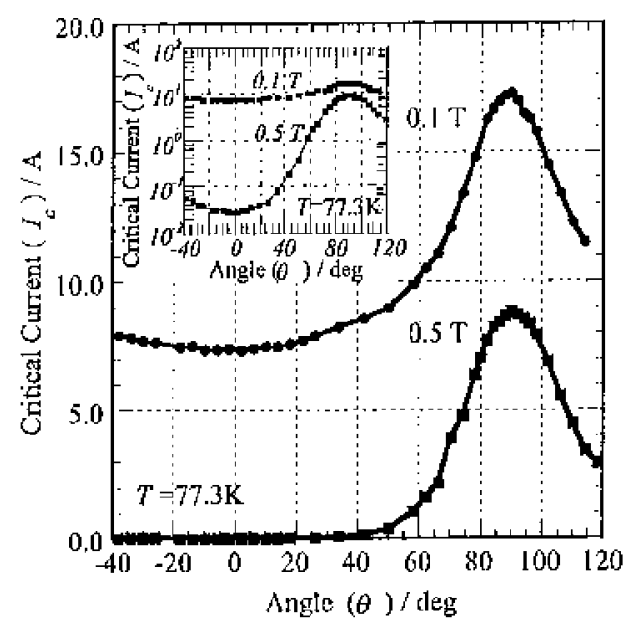

Fig. 2. Angular depentunces of critical currents $\left(s_{c}\right)$ at $\mu_{0} I_{e}=0.1$ and $0.5 \mathrm{~T}$, respectively. Inset shows the snmilog plots of the $I_{\mathrm{f}}=0$ culves.

\section{Rlisult's AND Discussion}

\section{A. Anisotropy of onitical currents}

Fig.2 shows the angular dependences with respect to the applied magnetic fiold direction of the critical currents for tho field of $0.1 \mathrm{~T}$ and $0.5 \mathrm{C}$ ', respectively. 'The voltage criterton of the critical current was $100 \mathrm{nV}$, which corresponds to the electric field critorion of the $0.5 \mu \mathrm{Vcm}^{-1}$. In this low voltage region, the effect of the sharing currents in the Ag shoath can be neglected. As is well known, strong anisotropy of $I_{c}$ values is ovident in Fig.2. Sunilog plots of $I_{c}-\theta$ features are also plotted ir the inset of Fig.2. As seen, the ratio of the $X_{\mathrm{c}}\left(\theta=90^{\circ}\right)$ and $I_{c}\left(\theta=0^{\circ}\right)$ varios drastically by increasing the applion ficld from $0.1 \mathrm{~T}$ to 0.5 T, i.c. $I_{c}\left(\theta=90^{\circ}\right) / I_{c}\left(\theta=0^{\circ}\right)=2.35$ for $/ \mu_{0} H_{c}=0.1 \mathrm{~T}$ and $I_{c}\left(\theta=90^{\circ}\right) / I_{c}\left(\theta=0^{\circ}\right)=305$ for $\mu_{0} H_{e}=0.5 \mathrm{~T}$, respectivoly.

As pointed out by Tinkham [5], if the superconductors are 2-dimensional, $I_{c}-\theta$ curve shows cuip at $\theta=90^{\circ}$. However, the obtained results show rather roundorl structure near the peak as seon in Fig.2. In this case, it's known that the anisotropy can be described by the oflectivo mass model [6]. Furthormore, we found oxponinentally that tho width near the peak of $I_{\mathrm{c}}-\theta$ curve increases as the so-called $n$-value of the voltage-urrent charactoristies docroases (Data will be reported olscwhere), Because tho $n$-value describes tho statistical clistribution of the local critical current densitios as pointed out by KKiss ot al, [7], it's to be deduced that the structure around the peak shows the inhomogenity of the samplo.

$I_{c}$ values are replottod with the nomal component of the applied magnotic fiold $\left(\mu_{0} H_{e} \cos \theta\right)$ in Fig.3. Solid symbols wore obtainod from Fig.2, and oth symbols were obtained from the applied field dopondort $Y_{c}$ data at a fixed anglo. It's shown that almost all $I_{0}$ clatia lic on the samo curvo ex-

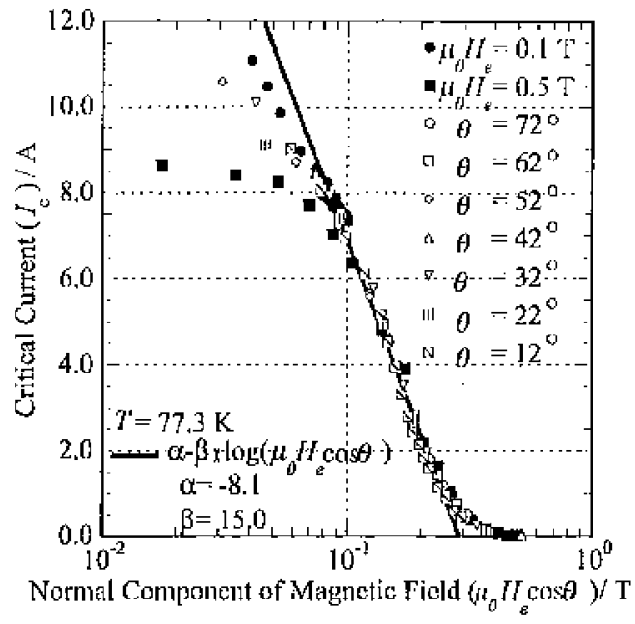

Hig. 3. $I_{u-p n} J I_{\mathrm{e}} \cos \theta$ charatoristics. Data were obtaind from Iig.2 (solid symbole), and frow fiuld dependent $I_{c}$ data at a fixal amglo (other symbola). Solid line was obtained by eq.(1).

cept at $\mu_{0} H_{e} \cos 0<0.1 \mathrm{~T}$. That is, $I_{c}$ vahus are dominated by the normal component of the applied magnetic field $i t h$ wide range of the field diroction. Howover, $I_{c}$ valnes tend to saturate at $\mu_{0} H_{\mathrm{e}} \cos \theta<0.1 \mathrm{~T}$ by deviating from the master curve, and the saturation values are decroased as tho appliod fields are incroased. Tho samo rosults have nlso bocr obtained by Honsel of al. [8]. 'This cas be explained by the misorientation of the crystals [8]. Furthemore, scaling curve for the amgulam doponclonco of critical currents has been proposol oxperimcntally by Kobayashi et al. [9], as follows,

$$
I_{c}=\alpha-\beta \log \left(\mu_{0} H_{\mathrm{e}} \cos \theta\right)
$$

Solid line in Fig.3 shows the fittod rosult by eq.(1) with $\alpha=-8.1, \beta=15.0$, As sen, magnetic fiold and angular dependences of the eritioal currents aro estirnated in a wide regiom with eq. (1).

\section{B. Anisotropty of current transport characteristics}

Magnotic field dependent current transport charucteristics as a function of tho field direction were studied. All moasurements woro porformul utder zero-fidd cooling condition. Typical oxaniple of the measured voltage-current. ( $V$ I) characteristics at the ficld direction of $42.0^{\circ}$ are shown as open circles in Fig.4. In ordor to obtain the precise $V$ $I$ curves of the superconductor, it's important to corroct tho sharing current flowing in the $\mathrm{H} g$ shoath. We assume tho sample as the parallal circuit of tho superconducting layer and the Ag shoath, then supercurrent flowing in the superconducting layer ( $I_{s c}$ ) will be corrected nsing tho measured curront $(I)$ and the sharing corrent flowing in the $\mathrm{Ag}$ shealh $\left(I_{a g}\right)$ as, $I_{s r}=I-I_{a g}=I-V / R_{a g}$. Whero, $R_{a g}$ is a resistance of the $\Lambda \mathrm{g}$ sheath. Solid circles in Fig.4 show tho corrected results. ITereatter, comected $V-I$ curves with $I_{g c}$ will be discussod. Fig.5 shows the magnetic fiold variation of tho $V-I_{s}$ chatncteristics at $\theta=12.0^{\circ}$. As scon, the curvature of $\log V-\log I_{s e}$ curves change from convox to 


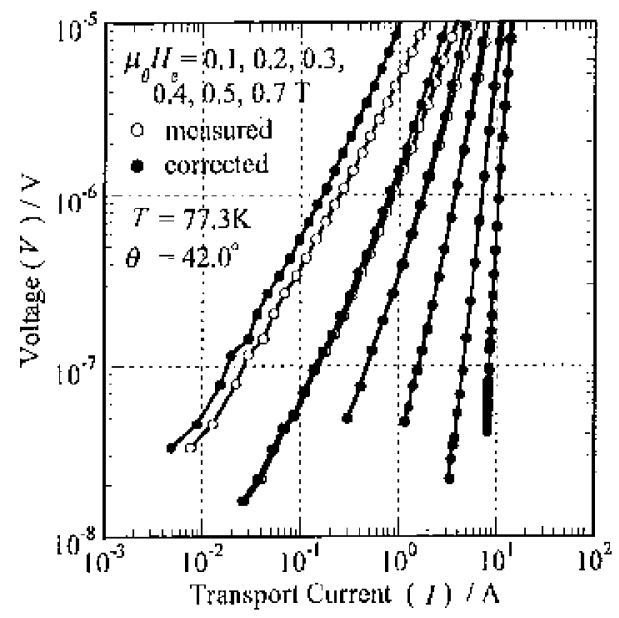

Fig. 4. Magnetic field dependence of the $V-I$ characteristic at $\theta=$ $\mid 2,0^{\circ}$. Opon and solid circles wore oblained for without and with the correction of sharing enrrents in the $A \mathrm{~g}$ sheath.

concave shape as the extemnal magnetic field increases. Wo define so-callod glass-liquid transition magnetic flux density $\left(B_{g}=0.16 \mathrm{~T}\right)$ at whitch $V-I_{y c}$ curve shows the powor law foature as shown by solid line in Fig.5 [3],[4]. Furthermore, all elurves are collapsed on two master curves by normalizing the $V$ to $\left(V / I_{s e}\right) /\left|B-B_{g}\right|^{p(z-1)}$, and $I_{s c}$ to $I_{s \mathrm{v}} /\left|B-B_{g}\right|^{2 / 2}$ as shown in Fig.6. Paranotors $z(=8.2)$ and $\nu(=0.6)$ clenote critical indices, and especially $z$ is proportional to the $n$-value at $B_{g}$. By separating fields with $B_{g}$, solicl and open circles wore obtained from $V-I_{s c \text { corves }}$ in lower and higkor ficlds, respectivoly. Mary models have brou proposod for the physical meaning of the scaling of $V-I_{\text {se }}$ curves $[3],[4],[10-12]$. Ilere, we focus on the importance of $B_{g}$ for the practical applications. That is, as secn in Fig.6, dissipation is induced exem applying small current in higher magnetic fiolls (open circles). On the other hinnl,

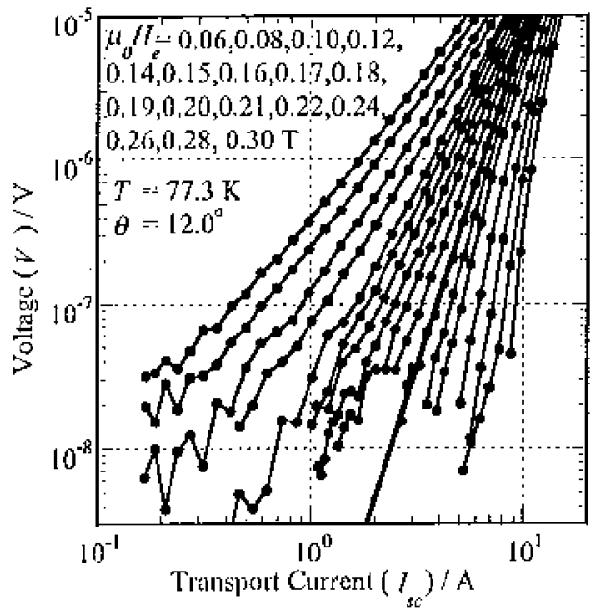

Fig. 5. Magnotic fieled dependence of the $V$ - $I_{s e}$ charactoristics at $0:=12,0^{\circ}$. Solid line shows the power-law charesteristics at socalled glass-liquid transilion flux donsity $\left(B_{y}\right)$

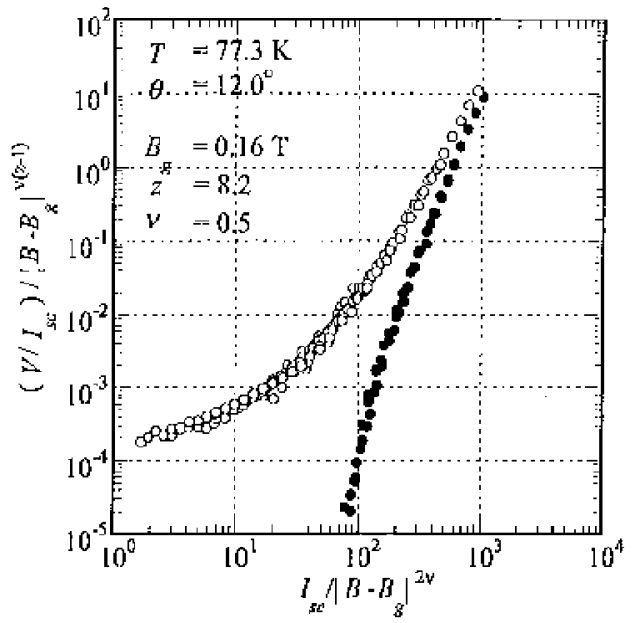

Fig. 6. Scaling collapses of the $V-I_{s c}$ curves obtainod from Fig.5. $B_{e}=0.16 \mathrm{~T}, z=8.2$, and $y=0.6$ wore obtained by the critical scaling analysis.

dissipation roduces drastically by decreasing the transport current in lowor fiolds (solid circles). 'Therefore, magnotic: ficld region adequately below $B_{q}$ has to be used for the design of the superconducting powor systoms with persistent current modo. In othor words, $B_{g}$ is one of the important inaterial parameters for such applications.

Fig.7 shows the $V-I_{s c}$ charactristics at $B_{g}$ for various field clircctions. As scen, all data lie on the same curve without depending on the field directions. Furthermore, $B_{2}$ s are plotted as a function of tho external magnotic field direction in Fig. 8. As shown, $B_{g}$ increases as $\theta$ increases. $B_{9}$ s are also plotted for $\cos ^{-1} \theta$ in Fig. 9 . As can be sem, $B_{g}$ is proportional to $\cos ^{-1} \theta$ at lower $\cos ^{-1} \theta$ region corresponding to the lowor anglo region. From these results, wo can say that not only eritical currents but also $B_{g}$ is only cominated by the normal component of the oxternal mag-

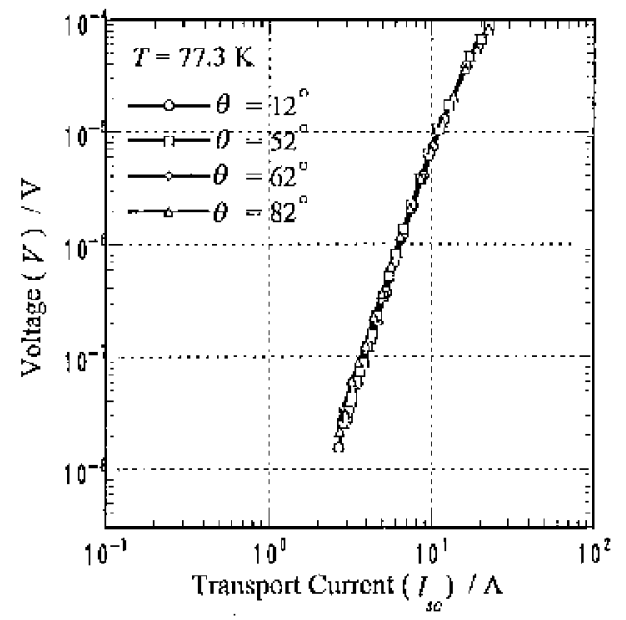

lijg. 7. $Y-I_{s c}$ characteristics at $I_{g}$ for various field direction. $\eta_{g}$ was determined as the magnetic flux density at which $V-I_{s c}$ curves show powor law features. 


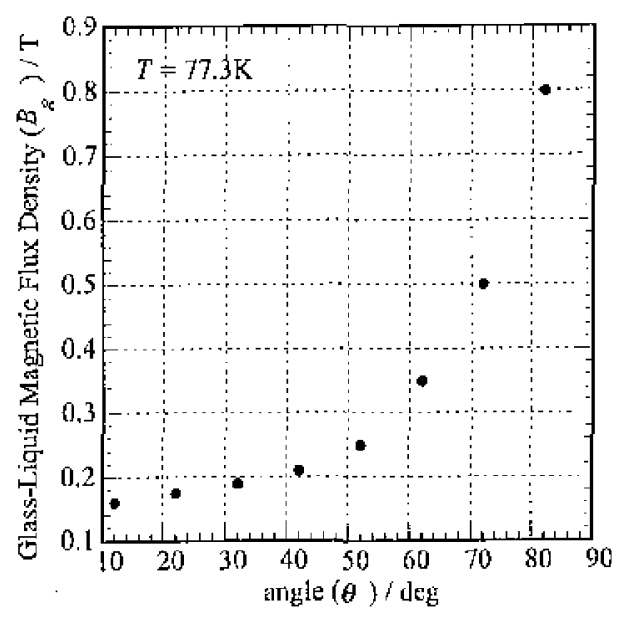

rig. 8. $B_{g}-0$ characteristics.

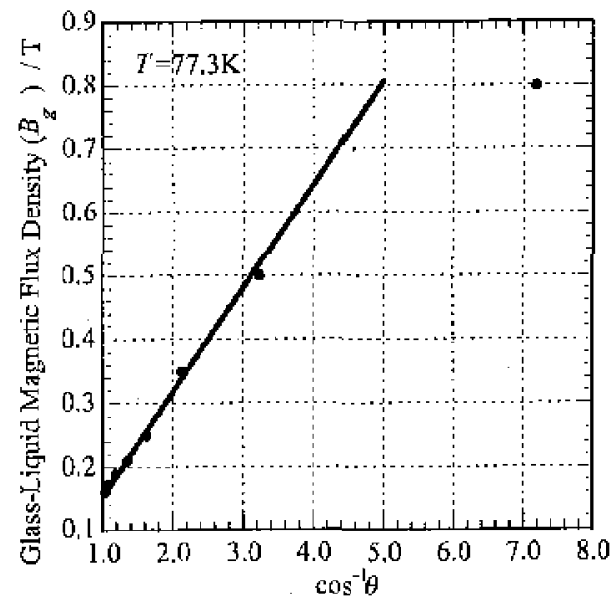

1'ig. 9. $B_{g}-\cos ^{-1} \theta$ charactaristics obtatiand from Fig, 8 ,

netic fiold. The doviation at higher angle region will be because of tho same reasom of that of $I_{c}-\theta$ characteristics in Fig. 3,

Aforementioned anisotropy is usually discussed by effective mass model. Based on the model, magnetic anisotropy is expressed by using that of the upper critical flux density $\left(B_{c 2}\right)$ as follows $[6]$,

$$
B_{c 2}(\theta)=B_{c 2}\left(0^{\circ}\right)\left[\cos ^{2} \theta+\left(\frac{B_{c 2}\left(0^{\circ}\right)}{B_{c 2}\left(90^{\circ}\right)}\right)^{2} \sin ^{2} \theta\right]^{-\frac{1}{2}}
$$

High- $T_{c}$ superconductors, however, are effected by the thermal fuctuation; and the definition of the $B_{c 2}$ is very ambiguous. Furtlormore, it's questioned whether cling transition occur at $B_{c 2}$ for high $-T_{c}$ superconductors. Thercfore, the anisotropy of the material paramerers has to be studied with consideration of the themual fluctuation such as $B_{g}$. More study is necessary for the accurate design of the high- $T_{\text {r: }}$ power systoms.

\section{CONCLUSION}

Critical currents and current transport characteristics in a mixed state of $\mathrm{Bi}-2223 / \mathrm{Ag}$ multifilamentary tajo werc studied as a function of the extemal magnetic fodd and the field direction. It was shown that the so-called glass-liquid transition magnetic flux density as well as tho critical curronts were determinol by the nozmal component of the extornal magnetic field in a wide range of the ficld direction. The importance of this parameter for the power applictitions with porsistent current modo was also discussed.

\section{ACKNOWIFDGMENTS}

The anthors would like to thank KERI staff for provicing samples.

\section{RTFFRENOES}

[1] T. Kato, K. Ohkura, M. Ueyama, K. Ohmatsu, K. Hayashi and K. Sato, "Development of Eligh-Tc Superconducting Magnet Using Ag-Sheathed Hi222.3 Tapes ", Procedings of 15th Internationa! Canference on Magnee ifechnology, part $\mathrm{i}$, jp. 793-796, 1998.

[2] K. l'ınaki, M. Twakuma, M. Takeo, K. Yarnafuji, J. Suehiro, M. Hara, M. Konno, Y. Kasagawa, I. Itoh, S. Nose, M. Ucyama, K. Flayashi and K. Sato, "Preliminary 'Tests of A 500kVA-Class Oxide Superconducting Transformer Cooled by subcooled Nitrogen" , ILWE Transactions on Applied Superconductivity, pp. 824-827, 1997.

[3] M. L. A. Fisher, "Vortex-Glass Superconductivi1y - A Possible Now Phase in Bulk IIigh-T $T_{c}$ Oxidns", Physical Review Letters, vol. 62, pp. 1415-1418, 1989 .

[4] F. IL. Koch, V. Foglietti and M. P. A. Fisher, Phys. Rev. Lett., vol. 64, Pp. 2586, 1900.

[5] M. Tinktharn, "Fiffect of Fluxoid Qtanulizalion on Transitions of Superconducting Films", Physical Revicw, vol. 129, pp. 2413-2422, 1963.

[6] W. F. Lawrence, S. Doniach, Procedings of the 12 h Intemational Conference on Low Temperature Phtrsics, Kyoto, wol.12, pp. 361, 1971.

[7] 'I'. Kiss, T. Nakamure, K. IFasegawa, M. Inoue, II. Okanoto, K. Punaki, M. 'Takno, K. Yamafuji and $\mathrm{F}$ '. Irie, "Nonlincar Resistance in High Tc Superconductors as a linction of Bias Chrront Density, 'lemperature and Magnetic Fiele]", Proceedings of the 17th Internathonal Cryogerio Highteering Conference, pp. 427-430, 1998.

[8] B. Hensei, I.C. Grivel, A. Jeromie, A. Perin, A. Pollini and R. Wibikger, "A model for the eritical current in $(\mathrm{Bi}, \mathrm{Pb})_{2} \mathrm{Str}_{2} \mathrm{Ca}_{2} \mathrm{Ou}_{x}$ silver-sheathed tapo: : 'The role of small-angle c-axis grain boundarieg and of the texture" , Flustca $C_{1}$ vol. 205, pp. 329-337, 1993.

[9] 5. Kobayashi, T. Kaneko, 'I', Kato, J. Fujikami and K. Sata, "A novel scaling of magnetic field dependencies of critical curcertis for Ag-sheathed Bi-2223 superconducting tape", Physica $G$, vol. 258, [?. 336-340, 1996.

[10] A. Fonghton, R. A. Pelcovitz and S. Subd(b, "Elux ]attice molting

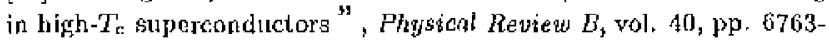
6770,1989 .

[11] 'I'. Matsushita, I', 'Lohdoh and N, Ihara, "Lffects of inhomogeneous flux pinting strength and flux flow on scaling of current-voltage characteristies in high-tomperature superconductors", Physich $C_{1}$ vol. 259, pp. 321-325, 1996. [12] K. Yamafuji and T. Kiss, "A new inl.erpretation of the glass-liquid transltion of pinned flukoids in high- $I_{\mathrm{c}}$. superconductors" , Physien C, pp. 196-212, 1996. 